when it is taken into the stomach because of the slower absorption and consequent more prolonged action. An additional reason for emphasizing the chloroform factor is the fact that it belongs to the same narcotic oroup as alcohol-the methane series-and produces similar effects.

116 Dithridge Street.

\section{MYASTHENIA GRAVIS}

FRANK W. ACKER, M.D.

DEXVER

I am reporting this case because of the rarity of the disease and to assist the profession in the diagnosis, should they meet with this condition. Some text-books do not mention it.

It is, as the name implies, a grave asthenia or fatigue of the musculature of the body, due to an exhausted condition of the nervous system. In this case, I did not make the diagnosis, but thought it a case of bulbar paralysis, so I called several consultants to help me out; but none of them had ever heard of such a condition, until 1)r. Hall was called. He immediately recognized it as myasthenia gravis.

\section{ETIOLOGY AND PATHOLOGY}

The etiology is obscure, but several theories are held. One theory is that it is produced by a toxin in the blood which causes the fatigue. Another theory is that it follows infections which cause a toxic neuritis. Link believes that it is due to lymphorrhagia into the museles, interfering with the lymphatic circulation, thus preventing the removal of fatigue products; but the majority of men seem to support the toxic theory.

The pathologic changes are mainly in the muscles, the nervous system being apparently normal in most cases. There occurs between the muscle fibers a lymphorrhagia, consisting of small lymphoid cells about again as large as red blood-cells; occasionally cells of larger type are found.

\section{REPORT OF CASE}

Patient.-M., aged 16, white, was of negative family history. The patient was a well-built girl for her age, with good color, and a well-developed body. She had always had the best of health until March, 1910. At that time she attended a dance in a very light gown, came out into the cold air in a very heated condition and rode home several miles. Since that time the symptoms enumerated below appeared and grew rapidly worse.

Symptoms.-Diplopia, ptosis of upper lids, difficult swallowing and chewing, collection of food in the cheeks, inability to control movements, especially after any kind of exercise; difficult respiration and tachycardia; difficult speech and pronunciation; weakness of neck muscles, causing the patient to rest her head against something; inability to eross knees; a lack of ambition and complaint of becoming tired after any small amount of exercise.

Course of Disease.-The patient's muscles became stiff, and it became more difficult for her to perform any movement She felt very much better in the morning after she had rested during the night. The urine was negative. The patient died from dyspnea and eardiac failure the same night that Dr. Hall was called in.

\section{DIAGNOSIS, PROGNOSIS AND TREATMENT}

I regarded the case as one of bulbar palsy, as it had so many of the symptoms of that condition; in fact, bulbar paralysis is a part of this disease. Besides the typical symptoms of this disease, in the diagnosis the myasthenic reaction can be used, which consists in the electrical examination of the muscles. If a rapidly intermittent current be applied to the affected mus:les, they respond well at first, but rapidly the contractions become less, until there is no response; this according to the degree of asthenia in the affected muscles.

The prognosis in these cases is, as a general rule, unfavorable. From one year to two years is the usual length of time the patient lives. My patient, from the time of the first symptoms, lived nine months.

In the treatment of this condition the following points should be observed:

1. All infections and toxic agents should be removed. 2. The patient should take rest. 3. Special attention should be paid to elimination. 4. Tonics such as strychnin and arsenic should be administered. 5. The diet should be of the highest concentration and easy of mastication, as the patient cannot chew and swallow well.

St. Joseph's Hospital.

\section{OPERATION FOR PEDUNCULATED EXOSTO- SIS OF' 'THE EXTERNAL AUDITORY MEATUS}

\section{S. B. MUNCASTER, M.D. \\ WASHINGTON, D. C.}

Exostoses of the auditory canal are at times as hard as ivory; it is almost impossible to cut them with the sharpest instrument or to drill them with the keenest burr.

A simple and easy method is to make a notched tooth saw out of No. 1 snare wire, or No. 1 piano wire. A piece of such wire twelve inches long is placed on a hard board and nicked obliquely one inch in the center of it, about 100 times. For this purpose, a sharp, heavy knife is used, the blade of which is not brittle. This will make sharp teeth that will saw through the hardest bone.

An application of cocain, 4 per cent., and solution of epinephrin, 1 to 1,000 , is made to contract the tissues and for local anesthesia. The canal is washed with solution of bichlorid of mercury, 1 to 5,000, using an ear svinge.

The wire tooth saw must be adjusted around the growth with an ear snare handle. After it is adjusted the assistant holds the wire in place while the operator withdraws the snare handle. The ends of the wire are then twisted around two pieces of wood-one and a half inches long and about one-fourth inch in diameter-for handles.

The base of the growth is then sawed through and ramoved with a pair of forceps. It is advisable to saw slowly to prevent heat and breaking of the wire. When the base is wider than the body of the growth this wire tooth saw will not be of any service.

If the patient is disposed to be nerrous, an anesthetic should be administered.

907 Sixteenth street.

Intracranial Complications of Middle Ear Disease.-A point of importance in diagnosis of intracranial complications se?ondary to middle ear disease, says $W$. Taylor in the Practitioner, is that when sinus infection is associated with any other intracranial complication, such as cerebral abscess, the phenomena of the sinus infection predominate, and signs char. acteristic of the other complaint will only manifest themselves after the sinus trouble has been removed by operation. 